\title{
Mechanical and electrical performance of Roystonea regia/glass fibre reinforced epoxy hybrid composites
}

\author{
GOVARDHAN GOUD* and R N RAO \\ Department of Mechanical Engineering, National Institute of Technology, Warangal 506 004, India
}

MS received 7 March 2011; revised 26 May 2011

\begin{abstract}
The present paper investigates mechanical and electrical properties of Roystonea regia/glass fibre reinforced epoxy hybrid composites. Five varieties of hybrid composites have been prepared by varying the glass fibre loading. Roystonea regia (royal palm), a natural fibre was collected from the foliage of locally available royal palm tree through the process of water retting and mechanical extraction. Roystonea regia, $E$-glass short fibres were used together as reinforcement in epoxy matrix to form hybrid composites. It has been observed that tensile, flexural, impact and hardness properties of hybrid composites considerably increased with increase in glass fibre loading. But electrical conductivity and dielectric constant values decreased with increase in glass fibre content in the hybrid composites at all frequencies. Scanning electron microscopy of fractured hybrid composites has been carried out to study the fibre matrix adhesion.
\end{abstract}

Keywords. Roystonea regia natural fibre; glass fibre; epoxy; hybrid composites; mechanical properties; electrical properties.

\section{Introduction}

Biocomposites are assuming much significance today due to growing environmental consciousness. Advantages of natural fibres over synthetic fibres such as glass and carbon are: low cost, low density, renewability, manufacturing ease and biodegradability. Natural fibres are being considered as potential reinforcement with both thermo plastic and thermoset matrices. Today natural fibre composites are widely used in automotive, furniture, construction fields. Natural fibre reinforced polyester composites are being used in engine and transmission covers of Mercedes-Benz buses. A good combination of mechanical properties and eco friendliness making natural fibre composites more attractive (Canter et al 2003). Jute, kenaf, flax, ramie and hemp are widely accepted for their good mechanical properties (Cicala et al 2009). Despite having several merits, natural fibre composites show lower modulus, lower strength and poor moisture resistance when compared with the composites reinforced with synthetic fibres such as glass and carbon. To overcome these limitations and to obtain great diversity of material properties, hybrid composites have been conceived wherein two or more fibres are reinforced in a single matrix ( $\mathrm{Li}$ et al 2000). In hybrid composites higher performance of synthetic fibre and environmental advantages of natural fibres are combined. Glass fibres are widely used these days with polymer matrices due to their higher strength, light weight, dimensional stability, resistance to corrosion, electricity etc. Several investigators developed hybrid composites by reinforcing natural fibres with glass

\footnotetext{
*Author for correspondence (pgovardhan0@yahoo.com)
}

and reported improved properties. Hybrid effect of glass and OPEFB fibre was calculated by Srikala et al (2002) and the study revealed overall improvement in the performance after hybridization. Raghavendra Rao et al (2010) found superior flexural and compressive properties with bamboo/glass fibre reinforced hybrid composites. Tensile properties of ridge gourd reinforced phenolic composites increased after hybridizing with glass fibres (Varada Rajulu and Rama Devi 2007). Though considerable literature is available on electrical properties of natural fibre composites, literature available on electrical properties, particularly dielectric properties of hybrid composites is very limited. Paul et al (1997) investigated the electrical properties of low-density polyethylene composites reinforced with short sisal fibres and a comparative study on dielectric properties of flax, hemp and oil palm fibres was conducted by Shinoj et al (2010). Dynamic mechanical and dielectric behaviour of bananaglass hybrid fibre reinforced polyester composites was studied by Pothan et al (2010). Volume resistivity and loss factor of banana/glass fibre-reinforced phenol formaldehyde hybrid composites were investigated by Joseph and Thomas (2008). In the present study, mechanical and electrical properties of Roystonea regia/glass fibre reinforced epoxy composites were studied.

\section{Materials and methods}

\subsection{Specimen fabrication}

Roystonea regia fibre was extracted from locally available Roystonea regia tree. Glass fibre supplied by the local 
supplier was used along with the Roystonea regia fibre as the reinforcement in the hybrid composite. Matrix material used was epoxy resin (Lapox-12) and hardener k-6 supplied by Atul Limited, Gujarat, India.

To obtain Roystonea regia fibre, leaves and leaf stem from the foliage sheath of Roystonea regia tree are separated and the sheath is dried for three days in shade. In the next step it was immersed in water retting tank for three weeks followed by hand rubbing and rinsing in water till the unwanted greasy material was dissolved and fine fibre was extracted. Finally the extracted fibre was once again washed thoroughly in plenty of clean water to remove the surplus waste. The obtained fibre was dried under sun for one week. The average diameter of the Roystonea regia fibre used for the composite preparation was between 0.2 and $0.3 \mathrm{~mm}$. Short Roystonea fibres of 5-8 mm length were obtained from the continuous fibres. Similarly glass fibres of size 5-8 $\mathrm{mm}$ length were obtained by cutting from the continuous fibre roving using electronic fibre cutting machine. Both Roystonea regia and glass fibres were dried in an oven at $80^{\circ} \mathrm{C}$ for $24 \mathrm{~h}$ to remove surface moisture. Both types of short fibres were intimately mixed. The mould box was prepared with the dimensions of $200(\mathrm{~L}) \times 150(\mathrm{~W}) \times 3.0(\mathrm{~T}) \mathrm{mm}$. Matrix was prepared by mixing the hardener to epoxy. The epoxy and hardener ratio was maintained at 10:1. Mould box was loaded with appropriate quantities of matrix and fibres in random orientation and finally the compression pressure of $170 \mathrm{KN}$ was applied evenly to achieve a uniform thickness of $3 \mathrm{~mm}$ and cured for $24 \mathrm{~h}$ at room temperature. Five different types of samples are prepared. The sample designation and the content details are listed in table 1 . The resultant material was randomly oriented Roystonea regia/glass fibre reinforced epoxy hybrid composite plate with dimensions $200 \times 150 \times$ $3 \mathrm{~mm}^{3}$.

\subsection{Tensile testing}

Tensile testing was done with the help of INSTRON-3369 model Universal Testing Machine. The test was conducted as per ASTM D 3039-76 standards at a cross head speed of $10 \mathrm{~mm} / \mathrm{min}$. The temperature was conditioned at $22^{\circ} \mathrm{C}$ with a humidity of $50 \%$. The specimen dimensions were $150 \times$ $15 \times 3 \mathrm{~mm}^{3}$. In each case, five samples were tested and the average values were reported.

Table 1. Composition and designation of composites.

\begin{tabular}{lccc}
\hline Designation & $\begin{array}{c}\text { Epoxy } \\
(\% \mathrm{wt})\end{array}$ & $\begin{array}{c}\text { Roystonea regia } \\
(\% \mathrm{wt} .)\end{array}$ & $\begin{array}{c}\text { Glass } \\
(\% \mathrm{wt} .)\end{array}$ \\
\hline 0G & 80 & 20 & 0 \\
$25 \mathrm{G}$ & 80 & 15 & 05 \\
$50 \mathrm{G}$ & 80 & 10 & 10 \\
$75 \mathrm{G}$ & 80 & 05 & 15 \\
$100 \mathrm{G}$ & 80 & 0 & 20 \\
\hline
\end{tabular}

\subsection{Flexural testing}

Flexural testing was done as per ASTM D 5943-96 standards using three-point bending method at a crosshead speed of $5 \mathrm{~mm} / \mathrm{min}$ and temperature of $22^{\circ} \mathrm{C}$ with a humidity of $50 \%$. The specimen dimensions were $100 \times 15 \times 3 \mathrm{~mm}^{3}$. The average of five samples was reported.

\subsection{Impact testing}

The impact testing was done as per ASTM D 256-88 by Izod impact machine with unnotched specimen. The specimen dimensions were $122 \times 13 \times 3 \mathrm{~mm}^{3}$. In each case, five samples were tested and the average values were reported.

\subsection{Testing of electric properties}

To determine electric properties of the hybrid composites, specimens of $25 \times 25 \times 3 \mathrm{~mm}$ dimensions were prepared and tested with HIOKI 3531Z-impedence meter as per capacitance method at $0.5,1,2,3,4$ and $5 \mathrm{MHZ}$ frequencies.

\section{Results and discussion}

\subsection{Tensile tests}

Table 3 shows variation of tensile strength, tensile modulus and \% elongation at break with glass fibre loading in hybrid composites. The total fibre loading (Roystonea regia and glass) of the composite was maintained at $20 \mathrm{wt} \%$. All the tensile properties i.e. tensile strength, tensile modulus and $\%$ elongation at break, linearly increased with glass fibre loading in hybrid composites. This is due to the fact that the strength and modulus of glass fibre is much higher than the strength and modulus of natural fibre. In a hybrid composite, properties of the composite depend on the modulus and $\%$ elongation at break of the individual reinforcing fibres. Table 2 shows various physical and mechanical properties of Roystonea regia and glass fibres. Increased dispersion of fibres with increased glass fibre loading could be another reason for enhanced tensile properties. Scanning electron micrographs of tensile fractured $25 \mathrm{G}$ and $75 \mathrm{G}$ designated hybrid composites are shown in figures 1(a) and (b).

Table 2. Physical and mechanical properties of Roystonea regia and glass fibres.

\begin{tabular}{lcc}
\hline Properties & Roystonea regia & Glass \\
\hline Density $\left(\mathrm{g} / \mathrm{cm}^{3}\right)$ & $0 \cdot 825$ & $2 \cdot 14$ \\
Diameter $(\mu \mathrm{m})$ & $200-300$ & $5-25$ \\
Tensile strength $(\mathrm{MPa})$ & 263 & 2500 \\
Youngs modulus $(\mathrm{GPa})$ & 21 & 55 \\
\% Elongation & 4.012 & 4.5 \\
\hline
\end{tabular}



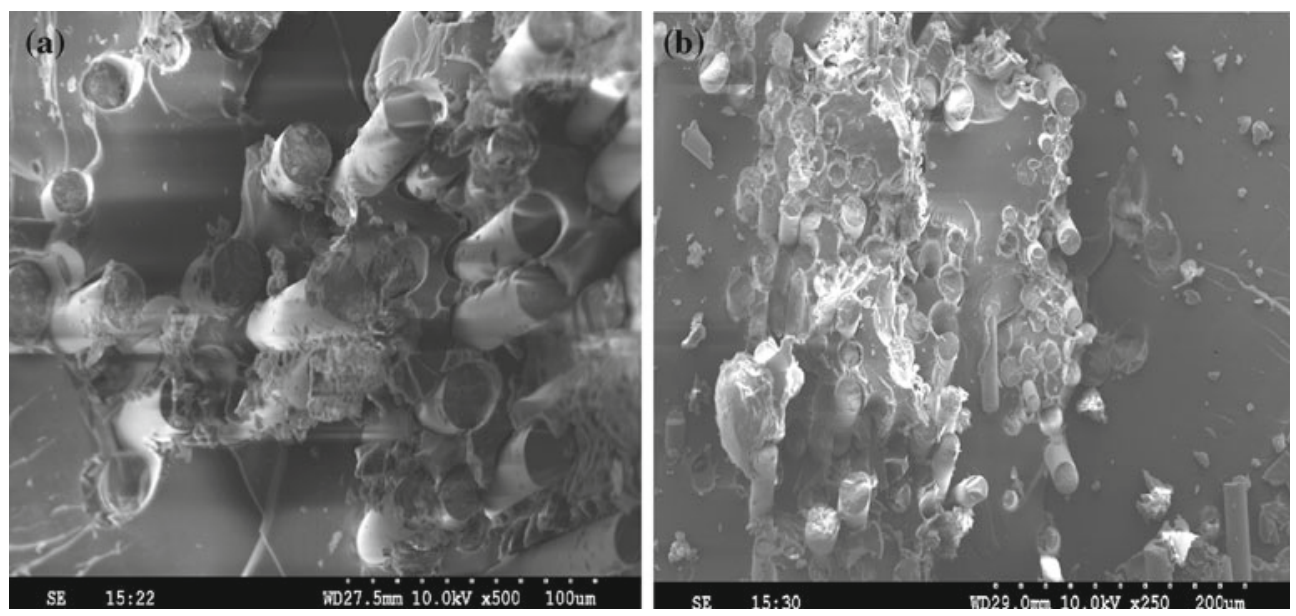

Figure 1. Scanning electron micrographs of tensile fractured surface of (a) 25G hybrid composite and (b) $75 \mathrm{G}$ hybrid composite.

Table 3. Variation of mechanical properties with weight percent Roystonea/glass fibre reinforced epoxy hybrid composites.

\begin{tabular}{|c|c|c|c|c|c|c|c|}
\hline $\begin{array}{l}\text { Hybrid } \\
\text { designation }\end{array}$ & $\begin{array}{l}\text { Tensile } \\
\text { strength } \\
(\mathrm{MPa})\end{array}$ & $\begin{array}{l}\text { Tensile } \\
\text { modulus } \\
(\mathrm{MPa})\end{array}$ & $\begin{array}{c}\% \\
\text { Elongation } \\
\text { at break }\end{array}$ & $\begin{array}{c}\text { Flexural } \\
\text { strength } \\
(\mathrm{MPa})\end{array}$ & $\begin{array}{l}\text { Flexural } \\
\text { modulus } \\
(\mathrm{MPa})\end{array}$ & $\begin{array}{c}\text { Impact } \\
\text { strength } \\
(\mathrm{J} / \mathrm{m})\end{array}$ & $\begin{array}{l}\text { Hardness } \\
\text { (Shore } D \text { ) }\end{array}$ \\
\hline $0 \mathrm{G}$ & $28 \cdot 86$ & 2386.48 & $1 \cdot 20$ & $39 \cdot 84$ & $3845 \cdot 81$ & $124 \cdot 23$ & 72 \\
\hline $25 \mathrm{G}$ & 31.98 & $2416 \cdot 42$ & 1.28 & $40 \cdot 12$ & 3982.42 & $151 \cdot 26$ & 73 \\
\hline $50 \mathrm{G}$ & 33.43 & $2522 \cdot 28$ & 1.69 & $46 \cdot 44$ & $3996 \cdot 25$ & 158.43 & 75 \\
\hline $75 \mathrm{G}$ & $34 \cdot 42$ & $2644 \cdot 32$ & $2 \cdot 11$ & $48 \cdot 66$ & $4011 \cdot 22$ & $168 \cdot 46$ & 82 \\
\hline $100 \mathrm{G}$ & $36 \cdot 42$ & 2888.43 & $2 \cdot 42$ & $52 \cdot 12$ & $4126 \cdot 18$ & $169 \cdot 33$ & 83 \\
\hline
\end{tabular}

\subsection{Flexural properties}

From table 3 it is evident that flexural strength and flexural modulus of hybrid composites increased with increase in glass fibre weight percentage. In flexural testing various mechanisms such as tension, compression, shearing take place simultaneously. With the addition of glass fibre shear resistance of the hybrid composite will increase (Mishra et al 2003) which will minimize shear failure. This will enhance the flexural properties.

\subsection{Impact strength}

The effect of glass fibre loading on impact strength of Roystonea regia/glass hybrid epoxy composites can be understood from table 3. The impact strength of $0 \mathrm{G}$ composite i.e. composites only with Roystonea regia reinforcement (without glass fibre) is $124.23 \mathrm{~J} / \mathrm{m}$ but $75 \mathrm{G} \mathrm{com-}$ posite i.e. hybrid composite with $15 \%$ (wt.) glass fibre has shown impact strength of $168.46 \mathrm{~J} / \mathrm{m}$. The impact strength increased by $26 \%$. Fibres play a vital role in impact strength of the composites as they act as stress transferring medium and interacts with crack formation. With increase in glass fibre content, inter fibre interaction will increase the effective stress transfer between fibre and reinforcement. This contributes to increase in impact strength. The scanning electron microscopy of $25 \mathrm{G}$ and $75 \mathrm{G}$ composites are shown in figures 2(a) and (b).

\subsection{Hardness (Shore D)}

From table 3 it is clear that shore $D$ values increased with increase in glass fibre content. This is due to the fact that hardness is density dependent and will increase with increase in density. The density of glass fibre is much higher than the density of Roystonea regia fibre. Hence increase in glass fibre loading would increase the hardness of the hybrid composite.

\subsection{Electrical properties}

Electrical conductivities of different hybrid composites at different frequencies are shown in figure 3. From the figure, conductivity increased with increase in frequency. This is mainly due to the additional contribution of finite-size clusters formed at higher frequencies. At excited frequencies, finite-size clusters (nano scale particles) bridge the gap 

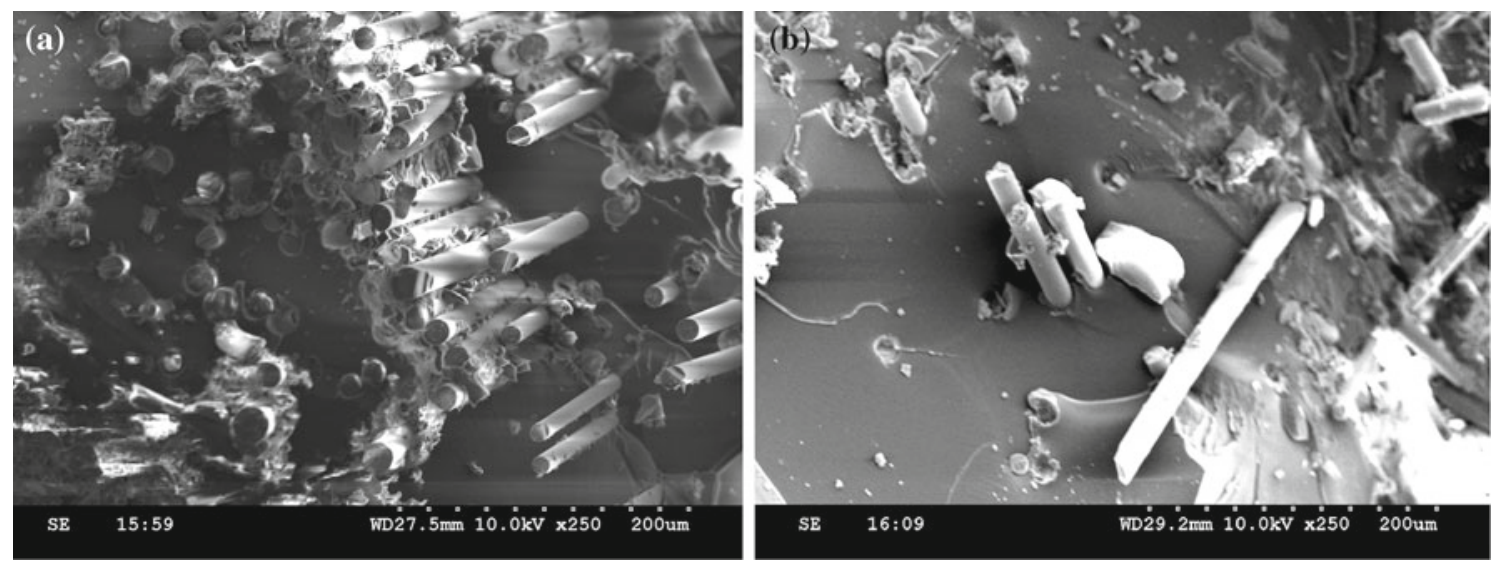

Figure 2. Scanning electron micrograph of impact fractured surface of (a) 25G hybrid composite and (b) $75 \mathrm{G}$ hybrid composite.

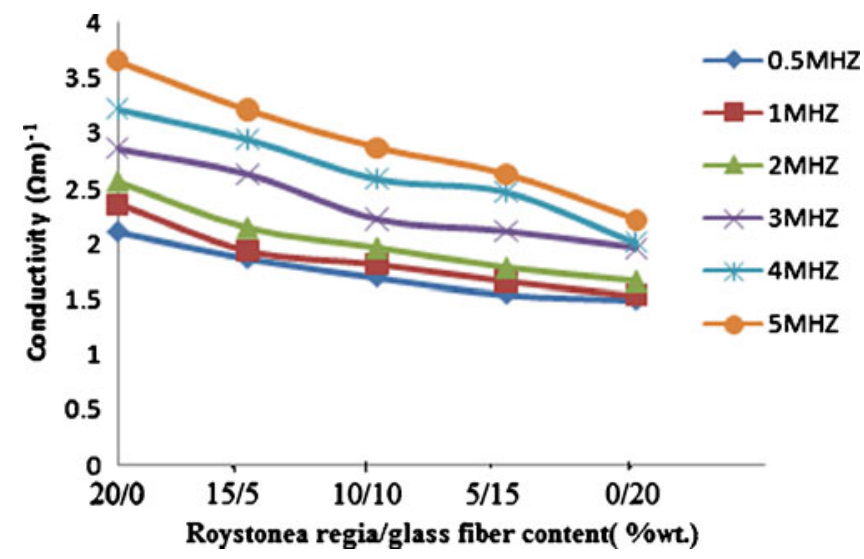

Figure 3. Variation of conductivity of hybrid composites at different frequencies as a function of Roystonea regia/glass fibre loading at total fibre content of $20 \%$.

between atoms/molecules and condensed matter. This will result in the increased conductivity. Also from the figure it can be observed that electrical conductivity decreased with increase in glass fibre content in the hybrid composites. This is because the properties of hybrid composites mostly depend on the properties of its constituents. The electrical conductivity of glass fibre is lower than the conductivity of the Roystonea regia fibre. Because of the hydrophilic nature, natural fibres are more conductive.

Figure 4 shows dielectric constant decreasing with increase in frequency and glass fibre loading in hybrid composite. At higher frequencies the time available for orientation will be very little; hence proper orientation of the molecules is not possible. Reduced orientation of polarization is the main cause for the decrease in dielectric constant with increase in frequency. Dielectric constant is polarization dependent. Decrease in dielectric constant with increase in glass fibre loading is mainly due to the reduced presence of the polar groups. The Roystonea regia fibre is lingo cellulosic and hydrophilic in nature and consists of more polar groups.

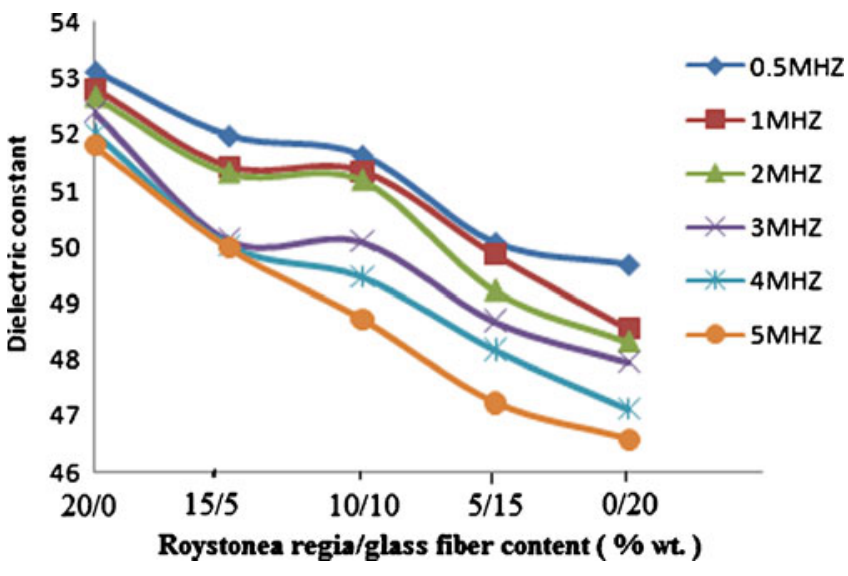

Figure 4. Variaton of dieletric constant of hybrid composites at different frequencies as a function of Roystonea regia/glass fibre loading at total fibre content of $20 \%$.

But glass fibre is hydrophobic and with the increase in glass fibre loading, there would be a corresponding decrease in natural fibre loading as the total weight of the reinforcement in hybrid composite is constant. With the decrease in natural fibre, presence of polar groups (polar water molecules) is reduced in the hybrid composite which results in lower dielectric constant values.

\section{Conclusions}

Replacing the Roystonea regia with glass fibre through hybridization leads to a considerable increase in tensile, flexural, impact and hardness properties. However, with the increase in glass fibre loading, electrical conductivity and dielectric constant values decreased at all frequencies. Hence it could be concluded that Roystonea and glass can be combined to produce hybrid composites to take full advantage of 
attractive mechanical properties along with low cost and ecofriendliness and these hybrid composites can be successfully employed in automotive and structural applications.

\section{References}

Canter G, Arbelaiz A, Llano-ponte R and Mondragon I 2003 Compos. Sci. Technol. 631247

Cicala G, Cristaldi G, Recca G, Ziegmann G, EL-Sabbagh A and Dickert M 2009 Mater. Design 302538

Joseph Seena and Thomas Sabu 2008 J. Appl. Polym. Sci. 109256 Li Y, Mai Y and Ye L 2000 Compos. Sci. Technol. 602037
Mishra S, Mohanty A K, Drzal L T, Misra M, Parijata S, Naik S K and Tripathy S S 2003 Compos. Sci. Technol. 631377

Paul Augustine, Joseph Kuruvilla and Thornas Sabu 1997 Compos. Sci. Technol. 5767

Pothan Laly A, George Chandy N, John Maya Jacob and Thomas Sabu 2010 J. Reinf. Plast. Compos. 291131

Raghavendra Rao H, Varada Rajulu A, Ramachandra Reddy and Hemachandra Reddy K 2010 J. Reinf. Plast. Compos. 291446

Shinoj S, Visvanathan R and Panigrahi S 2010 Bio. Sys. Engg. 106 378

Srikala M S, George Jayamol, Kumaran M G and Thomas Sabu 2002 Compos. Sci. Technol. 62339

Varada Rajulu A and Rama Devi R 2007 J. Reinf. Plast. Compos. 26629 